\title{
Web Services for Virtual Simulation
}

\author{
http://dx.doi.org/10.3991/ijoe.v10i5.3796 \\ Samir Akrouf ${ }^{1}$, Adel Merabet ${ }^{1}$, Ayoub Maza ${ }^{2}$, Djamel Boubetra ${ }^{1}$, \\ Larbi Selmani $^{1}$, Abdelhak Boubetra ${ }^{1}$, N Mouhoub ${ }^{1}$ \\ ${ }^{1}$ University of Bordj Bou Arreridj, Algeria \\ ${ }^{2}$ ALCOMSYS, Algeria
}

\begin{abstract}
Great development in distance learning has been made in the two last decade; the principal reason for that is due to the rapid evolution of technology, the huge development of computer networks, the large use of internet and personal computers. The World Wide Web with its different web services offers learners and teachers' new ways of learning and teaching; students can study at their own pace and perform practical works remotely.

We, at the University of Bordj Bou Arreridj, are involved in a TEMPUS project; its acronym is eSience which stands for rESeau maghrébIn de laboratoirEs à distaNCE, it aims to link three elabs around the Maghreb countries namely Algeria, Tunisia and Morocco. The project is coordinated by the University of Bordeaux 1, France with the participation of many other European partners. These elabs will propose practical and theoretical teaching units to their students and will be part of their degree program.
\end{abstract}

In this paper we present the architecture of the platform proposed by our university and we will focus on the web interface which permits to students to perform their practical works on the virtual simulator called SMARTSPICE of SILVACO. The first part of the paper is an introduction to the service broker, which will allow students from different universities (partners) to communicate and use their different platforms without having to enroll in the different platforms. In the second part we present the simulation server and give an example of its usage

Index Terms-Distance Learning, Virtual Simulator, Web Interface, Web Service.

\section{INTRODUCTION}

With the increase of the cost of equipments and software and the development of Internet bandwidth, distance learning becomes more and more important. It is a new way of learning and teaching; it gives the possibility of gathering many resources and shares their use. Thus, this will optimize their usage and reduces their cost.

This paper describes the design and development of web services for virtual simulation. The simulation is performed online via our distance learning platform [1] and is done remotely by students from the Maghrebian universities.

\section{BBA LAB ARCHITECTURE}

Here we describe the general architecture of the elab, as shown in Figure 1. We can see that a student from another university can access our platform and perform his simulation or enroll himself in an available teaching unit. He will pass through the service broker [2], which is the bond that will connect all the distant elabs of the different Maghrebian partners.

The service broker incorporates features that manage access rights and access permissions to the various catalog items. The service broker will handle the task of storage of data related to the experiences and activities resulting from the usage of external students' to our platform.

In the following we will describe the general features required in this platform and that the service broker has to accomplish as a proxy between the virtual labs and build a broad platform accessible to all the partners.

\section{A. Authentification of users:}

When a student tries to access to our platform the service broker authenticates him and gives him the right to connect, this is done by the following process as shown in Figure 2.

\section{B. Authorization:}

The service broker incorporates features that manage access rights and access permissions, for students, to the various items in the experimentations data base. Thus, they will have the right to realize the needed experimentations.

\section{Management of student files:}

The Service Broker records all the information of the student when he accesses the elab and realizes the experimentations.

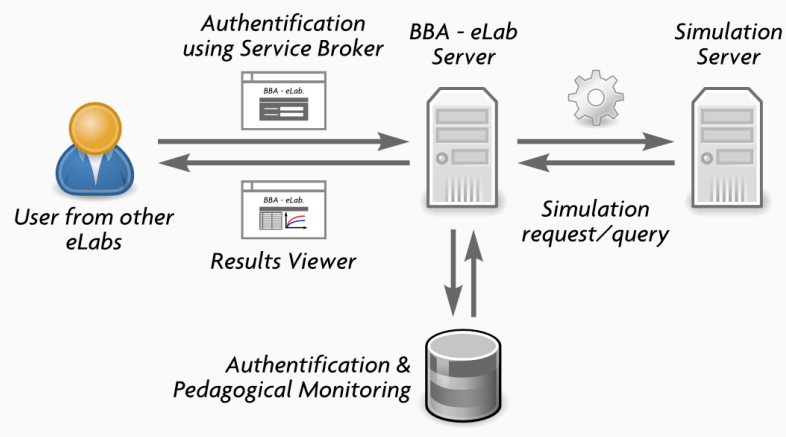

Figure 1. BBA - elab architecture
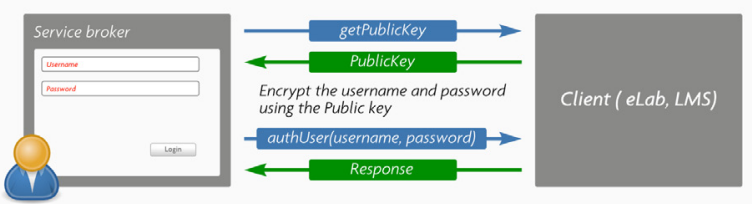

Figure 2. Identification via a service Broker 


\section{SPECIAL FOCUS PAPER \\ WEB SERVICES FOR VIRTUAL SIMULATION}

\section{Implementation of the Service Broker:}

Our service broker is designed as a web application. This application will be the access point to the content of our platform for students. Almost the entire operation of the service broker is based on the use and implementation of web services, which will allow the communication between all the stakeholders.

\section{E. External Architecture:}

The external architecture is an API interface that allows the Service Broker to communicate with other parts of the platform (client and server remote laboratory). In addition, it represents the boundary through which information circulates to and from the Service Broker.

This interface is divided into two main parts. The first part is an API server, which represents the services offered by the service broker and its clients. The second part is the client API, which is implemented by clients. The following figure, Figure 3., is the class diagram that describes the overall external architecture.

\section{THE BBA LAB SERVER}

The second part of the paper introduces the simulation server. This server is configured under Linux Red Hat Server Distribution. We acquired a license for AMS (Ana$\log$ and Mixed Signals) from SILVACO, which includes SMARTSPICE [3], an electrical circuit simulator, for device modeling, characterization and optimization of model parameters. The following figure, Figure 4., describes the general structure of the simulation server which will manage the simulation process:

Here we can notice that the simulation process will go through different steps allowing to students to choose out of three different methods; either entering their code, or using examples or finally entering the schematic of the circuit.

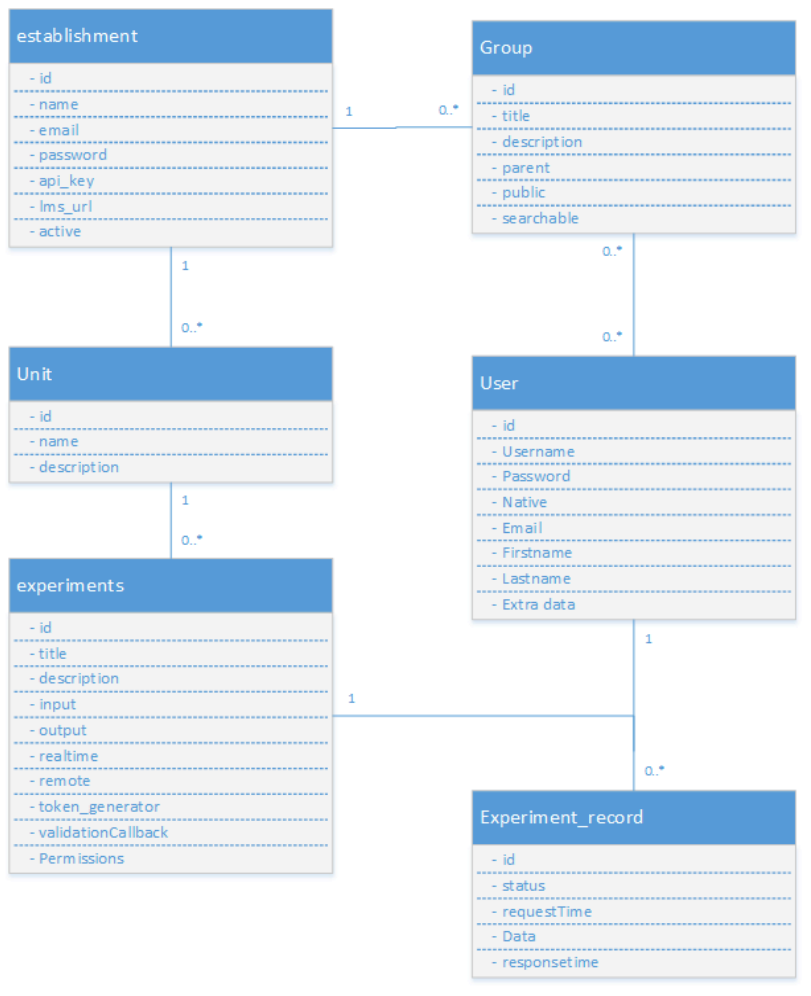

Figure 3. Class Diagram
The following is an example of the use of the server in order to get the characteristics of electronic circuits using SMARTSPICE deck-in to introduce the values of the different characteristics needed to perform the simulation. A set of measurements have been performed via Internet at the eLab remote characterisation platform of Bordeaux University to get electrical characteristics IDS (VDS), VDS sweeping from 0 to $3 \mathrm{~V}, \mathrm{VGS}=2.0$ and $3.0 \mathrm{~V}$, $\mathrm{VBS}=0.0 \mathrm{~V}$ [4][5]. Figure 5. is an interface used to introduce the data :

After running the simulation, as shown on Figure 6., we get the following results which are compared with the simulated and experimental characteristics after optimization. The curves are superposed (these curves were plot by Pylab, a tool from matplotlib [7]).

\section{CONCLUSION}

In this paper we presented the architecture of the platform we are developing for the eSience project in our university. In the first part we presented the service broker; its main features and the services it provides for the clients. In the second part we presented the architecture of the simulator server which allows to clients to do their simulation remotely.

It is important to notice that with the acquisition of the second software simulator, namely TCAD (Technological CAD) from SILVACO, which is a device modeling simulator who allows analyzing the internal electrical properties of a device [6], we will let the clients perform the whole process of simulation, beginning from the design and finishing by the optimization.

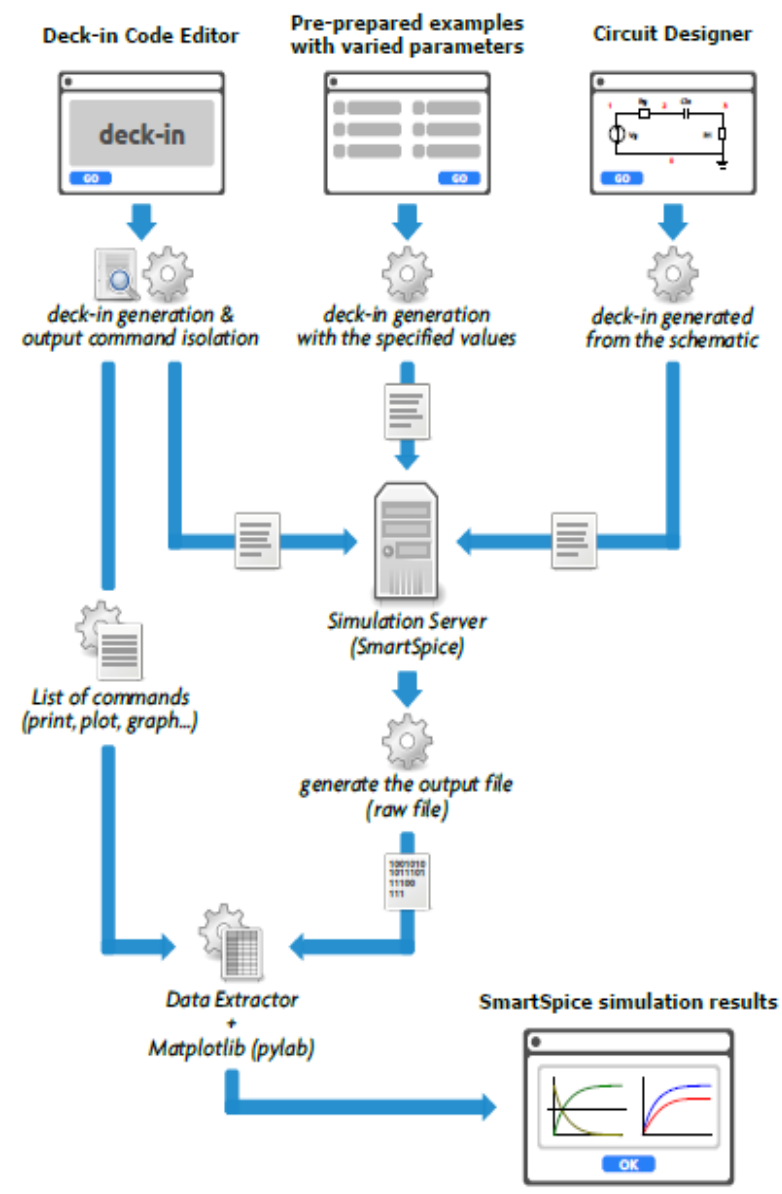

Figure 4. The General Structure of the Virtual Simulator 


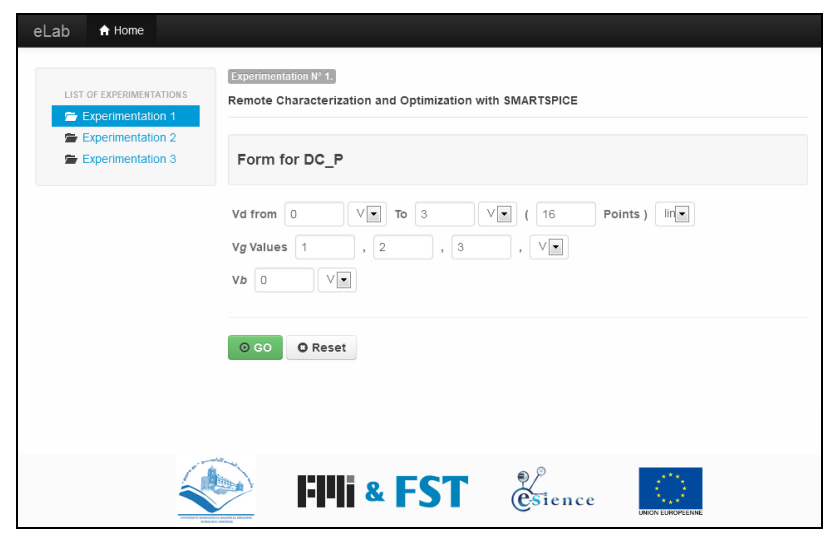

Figure 5. The Interface for introducing data for a predefined experimentation

Finally, we should say that throughout the development and the design of these web services and especially for the simulation server we developed a real application that parses clients' inputs and then launches the simulation process. The result is then formatted in a way that permits to the plotting tool to display the different curves for analyzing purposes.

\section{ACKNOWLEDGMENT}

The authors which to thank ALCOMSYS team, Professor Ferhat Hmida and Nacer Eddine Houria for their collaboration in the project. This project has been funded with support from the European Commission. This publication reflects the views only of the author, and the Commission cannot be held responsible for any use which may be made of the information contained therein.

\section{REFERENCES}

[1] T. Zimmer, M. Billaud, D. Geoffroy, "A remote laboratory for electrical engineering education”, IMCL2006 April 19 -21, 2006 Amman, Jordan.

[2] J. Santos, J. Mendonca, and J. C. Martins, "Instrumentation remote control through Internet with PHP," in Proc. IEEE VECIMS, Istanbul, Turkey, 2008, pp. 41-44..

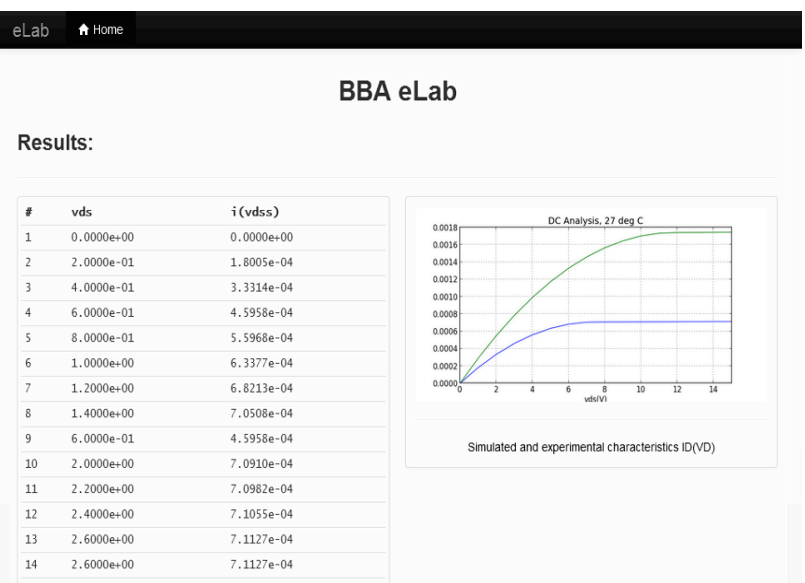

Figure 6. Simulated and Experimental Characteristics

[3] SmartSpice user's guide, www.silvaco.com

[4] Jean-Jacques Charlot, Larbi Selmani, Samir Akrouf, Djamel Boubetra, Abdelhak Boubetra, "Study and Utilization of Simulators Associated to Remote characterization of Circuits and Systems" International Conference on Engineering and Research July 1-5, 2013, Marrakesh Morocco.

[5] Samir Akrouf, Djamel Boubetra, Larbi Selmani, Boubetra, Abdelhak and Merabet Adel, "BBA Lab a V irtual Laboratory for Distance Learning". $20134^{\text {th }}$ International Conference On Distant Learning and Education (ICDLE 2013) Paris, France October 1213, 2013.

[6] Silvaco Technical Information, http://www.silvaco.com/tech lib/ index.html

[7] http://matplotlib.org/

\section{AUTHORS}

Samir Akrouf, Adel Merabet, Djamel Boubetra, Larbi Selmani, Abdelhak Boubetra, and N. Mouhoub are with University of Bordj Bou Arreridj, Algeria.

Ayoub Maza is with ALCOMSYS, Algeria .

Submitted 23 April 2014. Published as resubmitted by the authors 13 September 2014. 